\title{
Assessing biophysical controls on Gulf of Mexico hypoxia through probabilistic modeling
}

\author{
Daniel R. Obenour, ${ }^{1,2,5}$ Anna M. Michalak, ${ }^{3}$ and Donald Scavia ${ }^{1,4}$ \\ ${ }^{1}$ School of Natural Resources and Environment, University of Michigan, Ann Arbor, Michigan 48109 USA \\ ${ }^{2}$ University of Michigan Water Center, 214 South State Street, Suite 200, Ann Arbor, Michigan 48104 USA \\ ${ }^{3}$ Department of Global Ecology, Carnegie Institution for Science, 260 Panama Street, Stanford, California 94305 USA \\ ${ }^{4}$ Graham Sustainability Institute, 625 East Liberty Street, Suite 300, Ann Arbor, Michigan 48104 USA
}

\begin{abstract}
A mechanistic model was developed to predict midsummer bottom-water dissolved oxygen (BWDO) concentration and hypoxic area on the Louisiana shelf of the northern Gulf of Mexico, USA (1985-2011). Because of its parsimonious formulation, the model possesses many of the benefits of simpler, more empirical models, in that it is computationally efficient and can rigorously account for uncertainty through Bayesian inference. At the same time, the model incorporates important biophysical processes such that its parameterization can be informed by field-measured biological and physical rates. The model is used to explore how freshwater flow, nutrient load, benthic oxygen demand, and wind velocity affect hypoxia on the western and eastern sections of the shelf, delineated by the Atchafalaya River outfall. The model explains over $70 \%$ of the variability in BWDO on both shelf sections, and outperforms linear regression models developed from the same input variables. Model results suggest that physical factors (i.e., wind and flow) control a larger portion of the year-to-year variability in hypoxia than previously thought, especially on the western shelf, though seasonal nutrient loads remain an important driver of hypoxia, as well. Unlike several previous Gulf hypoxia modeling studies, results do not indicate a temporal shift in the system's propensity for hypoxia formation (i.e., no regime change). Results do indicate that benthic oxygen demand is a substantial BWDO sink, and a better understanding of the long-term dynamics of this sink is required to better predict how the size of the hypoxic zone will respond to proposed reductions in nutrient loading.
\end{abstract}

Key words: Bayesian modeling; dissolved oxygen modeling; Gulf of Mexico; hypoxia; nutrients; stratification.

\section{INTRODUCTION}

Hypoxia, typically defined by dissolved oxygen concentrations of less than $2 \mathrm{mg} / \mathrm{L}$, is a water-quality problem common to many coastal systems worldwide (Diaz and Rosenberg 2008). Hypoxia is often caused or exacerbated by anthropogenic nutrient inputs, though non-anthropogenic processes, such as stratification, are also known to affect its spatial and temporal variability (Rabalais et al. 2010). A particularly well-studied example of coastal hypoxia is the hypoxic zone along the Louisiana shelf of the northern Gulf of Mexico, USA (Rabalais et al. 2007a). Because Gulf hypoxia is largely driven by nutrient pollution from the Mississippi River basin, and because of ecological and economic concerns over the hypoxic zone, management action plans have been developed to reduce its average size to $5000 \mathrm{~km}^{2}$ or less (EPA 2008).

Quantitative modeling plays an important role in the management of Gulf hypoxia by synthesizing knowledge about the causes of hypoxia, and by predicting how the

Manuscript received 8 December 2013; revised 12 May 2014; accepted 1 July 2014. Corresponding Editor: M. C. Mack.

${ }^{5}$ E-mail: drobenour@ncsu.edu severity of hypoxia is affected by changing nutrient loads and other environmental factors (Scavia et al. 2004, Justic et al. 2007). Most existing Gulf hypoxia models can either be categorized as simple, in that they are more empirical and have little (or no) spatial detail (Greene et al. 2009, Turner et al. 2012), or complex, in that they are more mechanistic and provide richer spatial information (Bierman et al. 1994, Hetland and DiMarco 2008, Fennel et al. 2013).

The purpose of this study is to develop a model of intermediate complexity for assessing the relative importance of various biological and physical drivers of hypoxia on different sections of the Louisiana shelf. The resulting model has a parsimonious mechanistic formulation and a coarse spatial resolution, making it computationally efficient. As such, it can be calibrated within a probabilistic framework, thoroughly crossvalidated, and readily applied to developing scenarios relevant to water-quality management. At the same time, the model incorporates sufficient biophysical realism such that its parameterization can be informed by field-measured biological and physical rates. Like simpler hypoxia models, this model relies on a steadystate model solution, but it uses temporally referenced 


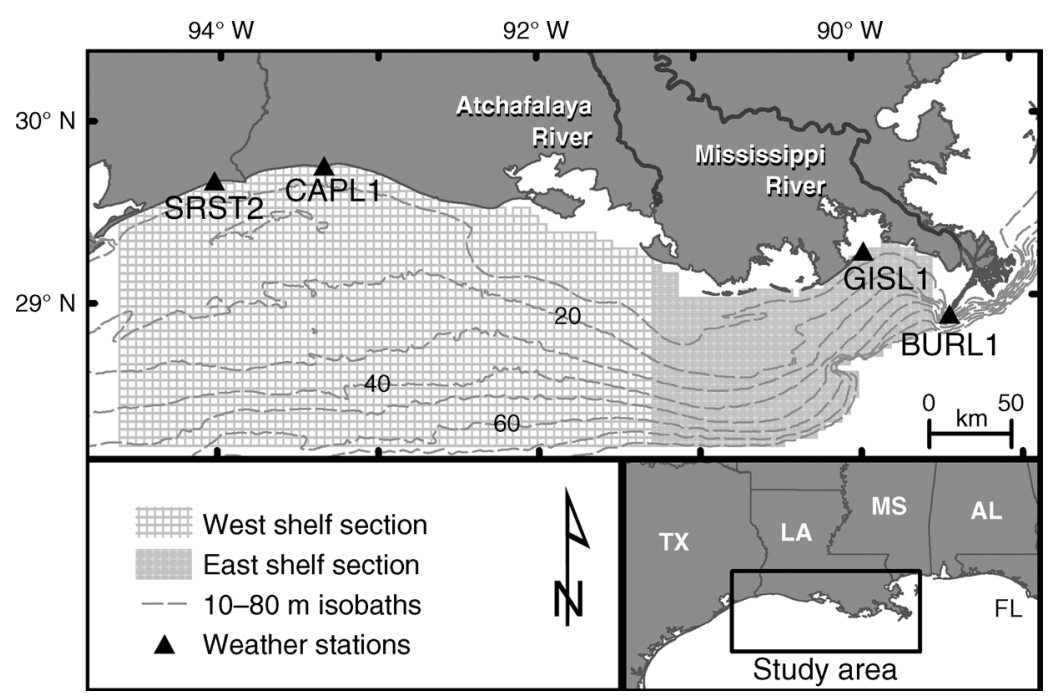

FIG. 1. Weather station (solid triangles) and isobath (dashed lines) locations in Louisiana shelf study area, USA.

inputs (such as wind stress) that are specific to the time of prediction. Thus, the model can be used to assess how factors such as nutrient loading, benthic oxygen demand, and wind control the temporal and spatial variability of hypoxia over a multidecadal study period (1985-2011). More broadly, this work helps address the need for probabilistic mechanistic models that can rigorously characterize scientific uncertainty and provide probabilistic scenario forecasts (Beck 1987, Clark et al. 2001, Reckhow 2003).

Another difference between this study and previous Gulf modeling studies is that it makes use of new estimates of mean bottom-water dissolved oxygen (BWDO) concentration and hypoxic area, as determined from a geostatistical model (Obenour et al. 2013). The geostatistical estimates were developed for midsummer conditions, based on dissolved oxygen measurements collected by the Louisiana Universities Marine Consortium (LUMCON) during annual monitoring cruises (Rabalais et al. 1999, 2007a). The geostatistical approach addresses biasing issues that were shown to affect previous hypoxic area estimates derived from these data. In addition, the geostatistical estimates include measures of uncertainty, related primarily to sampling coverage and types of sampling instruments used. These uncertainties are used in the present study, effectively giving more weight to estimates with lower uncertainty.

This work builds on previous studies that used largely empirical models to identify key anthropogenic and environmental factors related to Gulf hypoxia formation. All of these earlier models confirmed the relationship between midsummer hypoxia and spring nutrient load (Scavia et al. 2003, Turner et al. 2006, Scavia and Donnelly 2007). However, other studies have shown that river flow, which is significantly correlated with nutrient load, is also an effective predictor of hypoxia, such that the relative roles of nutrients and flows cannot be completely disentangled using empirical models alone (Wiseman et al. 1997, Forrest et al. 2011). Flows affect the degree of water-column stratification, which was confirmed to be another important predictor of dissolved oxygen (DO), along with nutrients, in a recent geostatistical modeling study (Obenour et al. 2012). The importance of both nutrients and stratification has also been demonstrated in mechanistic modeling of an intensely monitored location on the eastern shelf (Justic et al. 1996, 2002). In addition, multiple recent empirical and mechanistic modeling studies have found wind to be an important predictor of hypoxic area, likely because of wind's influence on transport and stratification (Forrest et al. 2011, Feng et al. 2012, 2013, Justic and Wang 2013). The present study provides a means of quantifying and comparing these relationships over a 27 -year study period (1985-2011) on the east and west Louisiana shelf.

\section{Materials And Methods}

\section{Data}

Midsummer mean dissolved oxygen concentration and hypoxic area are the primary response variables considered in this study. Results from a geostatistical model (Obenour et al. 2013) provide estimates of these variables, with associated uncertainties, for two sections of the Louisiana shelf, divided at the Atchafalaya River outfall location (Fig. 1). The west shelf section extends from 342.5 to $672.5 \mathrm{~km}$ Universal Trans Mercator (UTM) easting, and the east shelf section extends from 672.5 to $837.5 \mathrm{~km}$ UTM easting. The shelf sections represented in the model are limited to depths of 3-80 m, and to UTM northings greater than $3122.5 \mathrm{~km}$. Overall, the study area covers the regions where midsummer hypoxia is commonly observed. The geostatistical model inputs include only LUMCON DO measurements, 


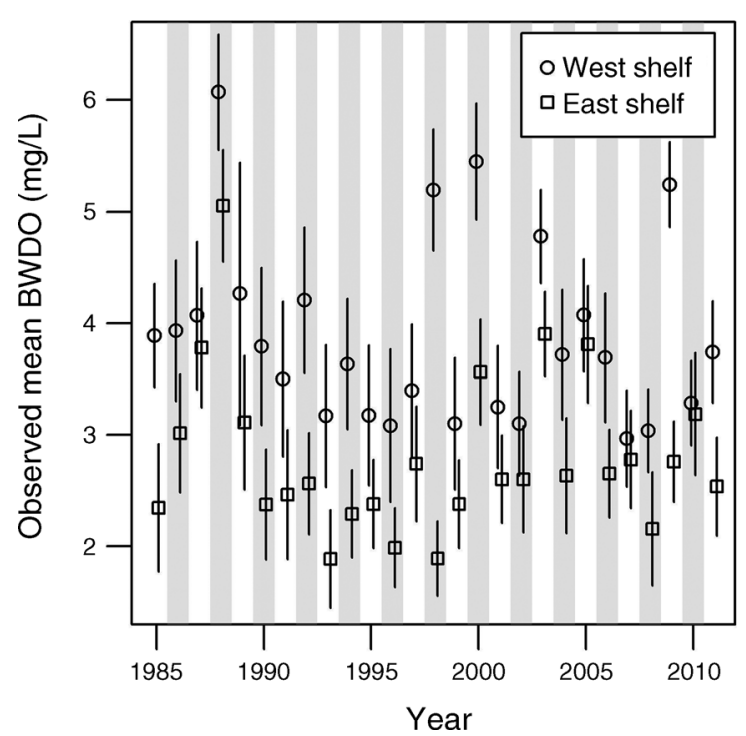

FIG. 2. Geostatistically determined observed midsummer mean bottom-water dissolved oxygen (BWDO), with $95 \%$ confidence intervals.

spatial coordinates, and bathymetry. No biophysical processes are represented in the geostatistical model, so the results provide an independent data set for calibrating mechanistic models. The uncertainties in the geostatistical estimates are approximately normally distributed, and are represented as such in this study (Fig. 2). For brevity, we refer to these geostatistical estimates of BWDO as observations.

The study uses United States Geological Survey (USGS) monthly flow and nutrient loading estimates (adjusted maximum likelihood estimator method; Runkel et al. 2004) for the Atchafalaya and Mississippi Rivers. ${ }^{6}$ Monthly flow and load estimates were interpolated (linearly) to determine loads for consecutive 30day averaging periods leading up to the starts of the annual shelfwide cruises (which began on different dates in different years). Previous studies have generally focused on total nitrogen (TN) or nitrate plus nitrite nitrogen $\left(\mathrm{NO}_{2}+\mathrm{NO}_{3}\right)$ loading data for modeling hypoxia (Scavia et al. 2004). While TN loads are naturally larger in magnitude than $\mathrm{NO}_{2}+\mathrm{NO}_{3}$ loads, they tend to be highly correlated and yield similar results in more empirical models (Forrest et al. 2011). However, because this model is mechanistically derived, the magnitude of the bioavailable nitrogen loading is important. TN includes $\mathrm{NO}_{2}+\mathrm{NO}_{3}, \mathrm{NH}_{3}$, and organic nitrogen $(\mathrm{ON})$, and while $\mathrm{NO}_{2}+\mathrm{NO}_{3}$ and $\mathrm{NH}_{3}$ are highly bioavailable, $\mathrm{ON}$ is more recalcitrant. Based on studies suggesting that about $60 \%$ of Mississippi River $\mathrm{ON}$ is dissolved (Goolsby and Battaglin 2001), and about $20 \%$ of dissolved $\mathrm{ON}$ is photochemically converted to $\mathrm{NH}_{3}$ on the shelf (Bushaw et al. 1996), 12\% of

${ }^{6}$ http://toxics.usgs.gov/hypoxia/mississippi/nutrient_flux_ yield_est.html river $\mathrm{ON}$ is represented as bioavailable in this study. Thus, the total bioavailable load is calculated as $\mathrm{NO}_{2}+$ $\mathrm{NO}_{3}+\mathrm{NH}_{3}+0.12 \times \mathrm{ON}$. Riverine dissolved organic carbon is not considered in the model because it is highly recalcitrant (Hernes and Benner 2003), and is expected to contribute negligibly to total shelf oxygen demand (Dagg et al. 2007).

The study uses coastal wind data for Sabine Pass, Texas (SRST2) and Southwest Pass, Louisiana (BURL1), retrieved from the National Data Buoy Center. $^{7}$ Additionally, data from Calcasieu Pass, Louisiana (CAPL1) and Grand Isle, Louisiana (GISL1) are used to augment missing data for Sabine Pass and Southwest Pass, respectively, after applying appropriate bias corrections (station locations are shown in Fig. 1). For brevity, we refer to the combined SRST2 + CAPL1 data set as the west data set, and the combined BURL1 + GISL1 data set as the east data set. Both data sets cover about $95 \%$ of the examined period, and mean monthly values are substituted for missing data. Data sets were used to determine daily east-west wind velocities, which were then averaged over 30-day consecutive periods leading up to the starts of the annual shelfwide cruises. In addition, weighted mean wind stresses (wind-speed squared) were determined for 14-day periods prior to the starts of the annual shelfwide cruises. Continuous monitoring data suggest that it takes approximately two weeks for DO to be re-depleted following wind mixing events (Walker and Rabalais 2006, Rabalais et al. 2007a), and linearly decreasing weights (14 down to one) are therefore assigned to wind stresses for each of the 14 days preceding a cruise. The wind data sets are applied to the different model segments by inverse distance weighting, using distances measured from primary weather station location to model segment centroid.

\section{Mechanistic model formulation}

This section describes the development of the mechanistic model. First, a series of differential equations (Eqs. 1-3) representing the primary biophysical processes related to BWDO depletion are presented, and these equations are solved for steady-state conditions (Eq. 4). Second, quasi-mechanistic sub-models for transport (Eq. 5) and reaeration (Eq. 6) are presented. Third, a distinction is made between spring (roughly late April through late June) model inputs that determine the water-column oxygen demand for each shelf segment, and summer (roughly late May through late July) model inputs that determine the reaeration conditions on each shelf segment.

Model segmentation is based on dividing the shelf east-west and vertically into four "mixed reactors" (Chapra 1997). The east-west division is at $672.5 \mathrm{~km}$ UTM easting (as described in the previous section). The

\footnotetext{
${ }^{7}$ http://www.ndbc.noaa.gov/
} 
west and east shelf sections have areas of 48500 and $14000 \mathrm{~km}^{2}$, and mean depths of 28 and $31 \mathrm{~m}$, respectively. The shelf sections are vertically divided at the pycnocline into upper and lower layers. The vertical division is nominally assumed to be at a depth of $10 \mathrm{~m}$ (Justic et al. 1996, Rabalais et al. 1999), though the exact location is not important to the model solution.

Nitrogen loads enter the model from the Mississippi and Atchafalaya Rivers, and they are converted to organic matter and fluxed to the lower layer based on an effective settling velocity $\left(v_{\mathrm{s}}\right)$. Overall, the differential equation for nitrogen in the surface layers is as follows:

$$
\frac{d N}{d t}=Q_{\mathrm{r}} C_{\mathrm{rN}}+Q_{\mathrm{u}} C_{\mathrm{uN}}-\left(Q_{\mathrm{r}}+Q_{\mathrm{u}}+Q_{\mathrm{g}}\right) C_{\mathrm{N}}-A v_{\mathrm{s}} C_{\mathrm{N}}
$$

Here, $d N / d t$ is the time rate of change for nitrogen mass in the shelf section $(\mathrm{Gg} / \mathrm{d})$, and variables $Q_{\mathrm{r}}, Q_{\mathrm{u}}$, and $Q_{\mathrm{g}}$ are flows $\left(\mathrm{Gm}^{3} / \mathrm{d}\right)$ entering the system from the rivers, upstream model segment, and Gulf, respectively. The variables $C_{\mathrm{rN}}, C_{\mathrm{uN}}$, and $C_{\mathrm{N}}$ represent nitrogen concentrations $(\mathrm{mg} / \mathrm{L})$ in the river, upstream model segment, and the subject model segment, respectively. Note that $Q_{\mathrm{r}} C_{\mathrm{rN}}$ is the river load $\left(L_{\mathrm{rN}}\right) . A$ is the area of the shelf section in $\mathrm{Gm}^{2}$.

The nitrogen that settles to the lower layer is generally associated with organic matter developed through primary production. The differential equation for organic matter (represented by carbon) in the lower layers is as follows:

$$
\frac{d C}{d t}=A v_{\mathrm{s}} R_{\mathrm{C}: \mathrm{N}} C_{\mathrm{N}}-V k_{\mathrm{C}} C_{\mathrm{C}}
$$

Here, $d C / d t$ is the time rate of change for carbon mass in the lower shelf segment $(\mathrm{Gg} / \mathrm{d}), V$ is segment volume $\left(\mathrm{Gm}^{3}\right), k_{\mathrm{C}}$ is the first-order decay rate for organic carbon (per day), $R_{\mathrm{C}: \mathrm{N}}$ is the ratio of organic carbon to nitrogen, and $C_{\mathrm{C}}$ is the concentration $(\mathrm{mg} / \mathrm{L})$ of organic carbon in the segment. Note that it is assumed that there is no advective flux laterally or longitudinally because bottom-water velocities are small relative to the temporal and spatial scales of this model (Rabalais et al. 1999).

Dissolved oxygen in the lower layer is lost through microbial decomposition of organic matter and regained through diffusion and mixing of DO from the surface layer. The differential equation for DO in the lower layers is as follows:

$$
\frac{d O}{d t}=A k_{\mathrm{a}}\left(C_{\mathrm{OS}}-C_{\mathrm{O}}\right)-V k_{\mathrm{C}} C_{\mathrm{C}} R_{\mathrm{O}: \mathrm{C}} \omega-A C_{\mathrm{O}} B / C_{\mathrm{OB}} .
$$

Here, $d O / d t$ is the time rate of change for oxygen mass in the shelf section $(\mathrm{Gg} / \mathrm{d}), k_{\mathrm{a}}$ is the reaeration rate $(\mathrm{m} /$ d), $C_{\mathrm{OS}}$ is the oxygen concentration of the overlying surface layer $(\mathrm{mg} / \mathrm{L}), R_{\mathrm{O}: \mathrm{C}}$ is the ratio of oxygen demand to organic carbon, $\omega$ is an oxygen demand adjustment factor related to processes such as photosynthetic oxygen production, $B$ is the benthic oxygen demand $\left(\mathrm{g} \cdot \mathrm{m}^{-2} \cdot \mathrm{d}^{-1}\right)$ at reference DO concentration $C_{\mathrm{OB}}(\mathrm{mg} / \mathrm{L})$, and $C_{\mathrm{O}}$ is the DO concentration $(\mathrm{mg} / \mathrm{L})$ in the lower layer. As shown, both the reaeration and benthic oxygen demand terms are affected by the segment DO concentration. Reaeration increases as the gradient between surface and lower-layer DO concentrations increases (Justic et al. 1996). Benthic oxygen demand increases as DO increases, and this relationship is approximated as linear (Lehrter et al. 2012).

Eqs. 1-3 can be solved together for $C_{\mathrm{O}}$ under steadystate conditions $(d N / d t=d C / d t=d O / d t=0)$, yielding

$$
C_{\mathrm{O}}=\frac{1}{k_{\mathrm{a}}+B / C_{\mathrm{OB}}}\left(k_{\mathrm{a}} C_{\mathrm{OS}}-\frac{R_{\mathrm{O}: \mathrm{C}} R_{\mathrm{C}: \mathrm{N}} \omega\left[Q_{\mathrm{r}} C_{\mathrm{rN}}+Q_{\mathrm{u}} C_{\mathrm{uN}}\right]}{\left(\left[Q_{\mathrm{r}}+Q_{\mathrm{u}}+Q_{\mathrm{g}}\right] / v_{\mathrm{s}}+A\right)}\right) .
$$

Eq. 4 is the primary mechanistic model formulation used in this study. However, the flows and loads used in Eq. 4 are determined by a transport sub-model, and $k_{\mathrm{a}}$ is determined by a reaeration sub-model. Note that terms $V$ and $k_{\mathrm{C}}$ (Eq. 3) cancel out when the system is solved for steady-state conditions (Eq. 4), and water-column oxygen demand is proportional to the organic matter flux from the surface layer. Also note that Eq. 4 predicts the DO concentration representative of the entire lower layer, whereas the geostatistical estimates are for BWDO (DO at the very bottom of the water column). Based on an analysis of DO profile data, BWDO concentrations are about $0.5 \mathrm{mg} / \mathrm{L}$ lower than DO concentrations near the middle of the lower layer, on average, and this adjustment is included within the model (i.e., $C_{\mathrm{BWDO}}=$ $\left.C_{\mathrm{O}}-0.5\right)$.

Coastal current patterns affect transport of freshwater and nutrients delivered to the Gulf by the Mississippi and Atchafalaya Rivers (Walker et al. 2005). Throughout much of the year, the dominant flow pattern is westward, and the strongest westward currents typically occur in spring, along the inner shelf, due to prevailing easterly winds and the buoyancy flux of river discharge (Cho et al. 1998, Zavala-Hidalgo et al. 2003, Zhang et al. 2012). In the model, transport of water and load is determined using a simple flow partitioning equation

$$
F_{\mathrm{e}}=0.5+\beta_{\mathrm{e}} W_{\mathrm{e}} .
$$

Here, $F_{\mathrm{e}}$ is the fraction of water and load transported to the east, $W_{\mathrm{e}}$ is the mean east-west wind velocity (westerly winds are positive, easterly winds are negative), and $\beta_{\mathrm{e}}$ is a transport coefficient determined through model calibration. To ensure that $F_{\mathrm{e}}$ is constrained to within the range $[0,1], W_{\mathrm{e}}$ is constrained to a range of $[-2,2] \mathrm{m} / \mathrm{s}$, and $\beta_{\mathrm{e}}$ is constrained to be calibrated within a range of $[0,0.25]$. The fraction of water and load transported west is simply $\left(1-F_{\mathrm{e}}\right)$.

Reaeration is represented using a quasi-mechanistic formulation based on flow and wind stress

$$
k_{\mathrm{a}}=\beta_{k 0}+\beta_{k 1} \tau /\left(Q_{\mathrm{s}} / A\right) .
$$

Here, $k_{\mathrm{a}}$ is the reaeration rate $(\mathrm{m} / \mathrm{d}), \tau$ is the 14-day weighted mean wind stress for the shelf section $\left(\mathrm{m}^{2} / \mathrm{s}^{2}\right)$, 
$\leftarrow$ Flow and load path $\bullet$ Partitioning location

$\leftarrow$ Flow only $\downarrow$ Load settling (to lower layer)

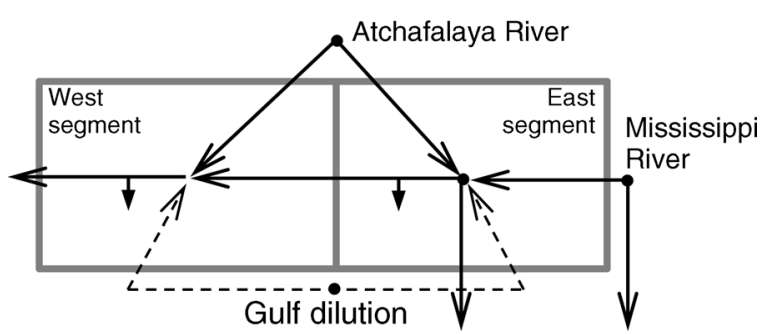

FIG. 3. Surface layer spring flow and load transport schematic for water movements in study area (east and west segments of the Louisiana shelf).

$A$ is the area of the shelf section $\left(\mathrm{Gm}^{2}\right)$, and $Q_{\mathrm{s}}$ is the summer freshwater flow onto the shelf section $\left(\mathrm{Gm}^{3} / \mathrm{d}\right)$. The model follows the logic that reaeration should increase due to wind-stress-induced mixing, but this mixing is inhibited by salinity stratification on the shelf section (represented by $Q_{\mathrm{s}} / A$ ). The terms $\beta_{k 0}$ and $\beta_{k 1}$ are essentially empirical parameters determined through model calibration.

The preceding descriptions make reference to spring and summer flows and loads. Spring flows and loads are expected to control the production of organic matter on the shelf, as represented in Eq. 4. Here, spring flows, loads, and east-west wind velocities are determined as weighted averages of 60-90-day and 30-60-day periods prior to the starts of the shelfwide cruises, with the earlier period receiving twice the weight of the later period. Because most cruises start in late July, this roughly corresponds to a period of late April-late June, but more heavily weighted toward the beginning of this period. This period approximately coincides with previous modeling studies suggesting May or May-June nutrient loads correlate best with hypoxic zone size (Scavia et al. 2004, Greene et al. 2009, Turner et al. 2012).

The transport of spring freshwater flows and nutrient loads is controlled by the spring east-west winds and the flow-partitioning sub-model (Eq. 5, Fig. 3). In the spring, $80 \%$ of the Mississippi River discharge (flow and load) is assumed available for partitioning, while the remaining $20 \%$ of Mississippi River discharge is assumed lost to the south or east under any wind condition (Walker et al. 2005, Zhang et al. 2012). Mississippi discharge partitioned to the east leaves the study area, while discharge partitioned to the west enters the east shelf section. The discharge from the Atchafalaya River and the Gulf dilution flow $\left(Q_{\mathrm{g}}\right)$ are both also partitioned, such that the westward partition enters the west shelf section, and the eastward partition enters the east shelf section. Flow and load within the east shelf section are partitioned, such that the westward partition enters the west shelf section and the eastward partition exits the model. Transport from the west shelf section back to the east shelf section could not be represented within a steady-state model. However, this type of eastward transport is expected to be rare in spring, as river flows become entrained in the dominantly westward spring shelf current (Wang and Justic 2009, Zhang et al. 2012).

Summer freshwater flow is expected to regulate the intensity of stratification and reaeration (Eq. 6) on the shelf at the time of the shelfwide cruises. The summer flows and east-west wind velocities are determined as weighted averages of the 30-60-day and 0-30-day periods prior to the starts of the shelfwide cruises, with the later period receiving twice the weight of the earlier period. Because most cruises start in late July, this roughly corresponds to a period of late May-late July (but more heavily weighted toward the end of this period). The total flow from this period correlates well $\left(r^{2}=0.8\right)$ with the intensity of stratification determined from a previous study by Obenour et al. (2012).

The summer freshwater flow to each shelf section, $Q_{\mathrm{s}}$, is determined by partitioning the summer Atchafalaya River discharge based on the transport sub-model (Eq. 5). Mississippi River discharge is not included in $Q_{\mathrm{s}}$ because relatively little Mississippi River flow enters the shelf in summer due to reversal of the westward coastal current (Walker et al. 2005, Zhang et al. 2012), and stable isotope studies suggest Atchafalaya River discharge constitutes the majority of freshwater in the surface waters of the shelf by midsummer (Strauss et al. 2012).

\section{Prior information and model calibration}

The mechanistic model includes several parameters determined through calibration or specified as known. The parameters listed in Table 1 are calibrated within the model by Bayesian inference, implemented using the WinBUGS program (Lunn et al. 2000) called from R (R Development Core Team 2008) via the R2WinBUGS software package (Sturtz et al. 2005, Gelman and Hill 2007). The Bayesian inference approach can incorporate prior information, rigorously account for parameter and data uncertainty, and be applied to nonlinear model formulations, such as Eqs. 4 and 6 (Stow et al. 2007). Prior information (i.e., a probabilistic expectation based on existing knowledge of the system) for model parameters is represented as probability distributions, as shown in Table 1. For most parameters, the priors are wide uniform distributions that are nearly noninformative (they are only narrow enough to prevent the inference process from occasionally reverting to unrealistic local minima). However, an informative normal prior distribution is used for benthic oxygen demand, based on recent research by Lehrter et al. (2012), who performed an extensive study of shelf sediment fluxes, and determined a mean benthic oxygen flux of 0.28 $\mathrm{g} \cdot \mathrm{m}^{-2} \cdot \mathrm{d}^{-1}$ with standard error $0.06 \mathrm{~g} \cdot \mathrm{m}^{-2} \cdot \mathrm{d}^{-1}$. A less informative normal prior was used for $\omega$, which represents an adjustment in water-column oxygen 
TABLE 1. Prior information for mechanistic model parameters to be determined by Bayesian inference.

\begin{tabular}{llll}
\hline \hline Symbol & \multicolumn{1}{c}{ Description } & \multicolumn{1}{c}{ Prior } & Unit \\
\hline$v_{\mathrm{s}}$ & effective settling velocity & $\mathrm{U}(0.01,1.0)$ & $\mathrm{m} / \mathrm{d}$ \\
$\omega$ & oxygen demand adjustment & $\mathrm{N}(0.5,0.2)$ & \\
$r_{\mathrm{Qg}}$ & ratio of Gulf flow to mean Mississippi flow & $\mathrm{U}(1.0,6.0)$ & \\
$B$ & benthic oxygen demand & $\mathrm{N}(0.28,0.06)$ & $\mathrm{g} \cdot \mathrm{m}^{-2} \cdot \mathrm{d}^{-1}$ \\
$\beta_{\mathrm{e}}$ & flow partitioning & $\mathrm{U}(0,0.25)$ & \\
$\beta_{k 0}$ & reaeration intercept term & $\mathrm{U}(0,0.5)$ & $\mathrm{m} / \mathrm{d}$ \\
$\beta_{k 1}$ & reaeration term modifying $\tau /\left(Q_{\mathrm{s}} / A\right)$ & $\mathrm{U}(0.05,0.5)$ & \\
\hline
\end{tabular}

Notes: U(lower bound, upper bound) is the uniform distribution, N(mean, standard deviation) is the normal distribution. Parameters with no unit specified are unitless. Variable $\tau$ represents the 14day weighted mean wind stress for the shelf section being modeled $\left(\mathrm{m}^{2} / \mathrm{s}^{2}\right), Q_{\mathrm{s}}$ the summer freshwater flow onto the shelf section $\left(\mathrm{Gm}^{3} / \mathrm{d}\right)$, and $A$ the area of the shelf section $\left(\mathrm{Gm}^{2}\right)$.

demand related to a number of factors. The prior mean ( 0.5 [unitless]) reflects studies suggesting that upward of $40 \%$ of sub-pycnocline oxygen demands are offset by photosynthetic oxygen production (Rowe 2001, Lehrter et al. 2009). Other factors that could be reflected in $\omega$ include off-shelf losses, nutrient recycling between layers, and inaccuracies in assumptions regarding load utilization (fraction of load that enters the shelf, fraction that is bioavailable, etc.). There is no strong evidence for the importance of these other factors, but the uncertainty in this prior reflects their potential relevance. Finally, a moderately informative uniform prior is used for $r_{\mathrm{Qg}}$, the ratio of Gulf flow to mean Mississippi River flow $\left(Q_{\mathrm{g}}=r_{\mathrm{Qg}} \times\right.$ mean $\left.\left[Q_{\text {Miss }}\right]\right)$. A previous study suggests this ratio is approximately 5-6 [unitless] under easterly winds (Walker et al. 2005). However, because river flow does not mix completely with Gulf flow, the effective dilution may be lower, and thus a uniform prior of $[1,6]$ is used.

Some modeling parameters can be reasonably specified as known because the uncertainty associated with these parameters is relatively small, and calibrating them would be computationally expensive while providing little additional scientific insight. The ratio of carbon to nitrogen, $R_{\mathrm{C}: \mathrm{N}}$, is based on the Redfield ratio $(5.68 \mathrm{~g} \mathrm{C} / \mathrm{g}$ $\mathrm{N}$; Redfield et al. 1963). The ratio of oxygen demand to carbon, $R_{\mathrm{O}: \mathrm{C}}$, is based on stoichiometric relationships for the aerobic decomposition of organic matter $(3.5 \mathrm{~g}$ O/g C; Justic et al. 1996, Chapra 1997). A surface-layer oxygen concentration, $C_{\mathrm{OS}}$, of $7.5 \mathrm{mg} / \mathrm{L}$ is used, based on an examination of surface-layer DO data. The reference oxygen concentration for benthic oxygen demand, $C_{\mathrm{OB}}$, is simply the DO concentration $(3 \mathrm{mg} /$ L) corresponding to the prior information for $B$ (Lehrter et al. 2012). Any uncertainty in these parameters is expected to be largely reflected through the oxygen demand adjustment factor, $\omega$.

The model also makes use of prior information for modeling output, particularly the vertical (downward) organic matter flux ( $v_{\mathrm{s}} R_{\mathrm{C}: \mathrm{N}} C_{\mathrm{N}}$ per Eq. 2). Sediment trap experiments by Redalje et al. (1994), suggest east shelf summer carbon fluxes of $0.18-0.40 \mathrm{~g} \mathrm{C} \cdot \mathrm{m}^{-2} \cdot \mathrm{d}^{-1}$. Thus, east shelf carbon flux is calibrated to an observed mean carbon flux, represented as a normal distribution, $\mathrm{N}(0.29,0.05) \mathrm{g} \mathrm{C} \cdot \mathrm{m}^{-2} \cdot \mathrm{d}^{-1}$.

Both mechanistic model uncertainty and geostatistical observation uncertainty are accounted for within the Bayesian framework using the following relationship:

$$
C_{\mathrm{geo}(i, j)} \sim \mathrm{N}\left(C_{\operatorname{mech}(i, j)}, \sqrt{\sigma_{\mathrm{geo}(i, j)}^{2}+\sigma_{\mathrm{mech}(j)}^{2}}\right) .
$$

In Eq. 7, $i$ and $j$ represent the cruise year and shelf section, respectively. The term $C_{\text {geo }(i, j)}$ represents the mean BWDO concentrations from the geostatistical model (these are the observations to which the mechanistic model is calibrated), and $C_{\operatorname{mech}(i, j)}$ represents the mechanistic model predictions. Mechanistic model (residual) uncertainties for the two shelf sections, $\sigma_{\operatorname{mech}(j)}$, are parameters determined through the Bayesian inference process, using an effectively uninformative prior distribution, $\mathrm{U}(0.1,3) \mathrm{mg} / \mathrm{L}$. Geostatistical uncertainty, $\sigma_{\mathrm{geo}(i, j)}$, is specific to each year and shelf section, as determined by the geostatistical model.

\section{Predicting hypoxic area from $D O$}

Mean BWDO results can be converted to hypoxic area using a linear regression between the BWDO and hypoxic area values from the geostatistical model. Because the relationship between mean BWDO and hypoxic area is nonlinear, both mean BWDO and mean BWDO squared are used as predictors. (The relationship is nonlinear because as mean BWDO increases to higher values, well above the hypoxic threshold, the hypoxic area becomes smaller and less sensitive to further increases in BWDO.) The resulting regressions for west and east shelf hypoxic area are as follows:

$$
\begin{aligned}
& A_{\mathrm{w}}=58230-18390\left(C_{\mathrm{BWDO}, \mathrm{w}}\right)+1460\left(C_{\mathrm{BWDO}, \mathrm{w}}\right)^{2}, \\
& A_{\mathrm{e}}=16950-5530\left(C_{\mathrm{BWDO}, \mathrm{e}}\right)+440\left(C_{\mathrm{BWDO}, \mathrm{e}}\right)^{2} .
\end{aligned}
$$

These regressions explain $98.5 \%$ and $98.7 \%$ of the variability in hypoxic area on the west and each shelf section, respectively (indicated by w and e subscripts), as estimated using the geostatistical model (Obenour et al. 2013). 


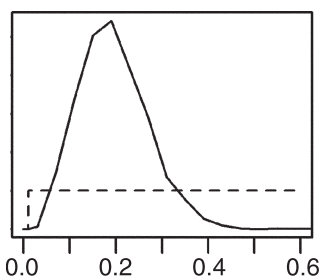

$v_{\mathrm{s}}(\mathrm{m} / \mathrm{d})$

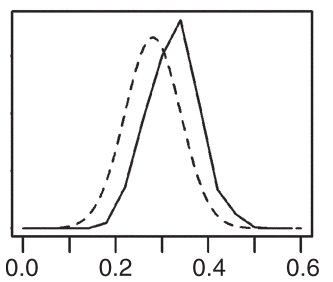

$B\left(\mathrm{~g} \cdot \mathrm{m}^{-2} \cdot \mathrm{d}^{-1}\right)$

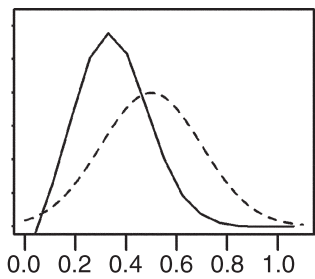

$\omega$

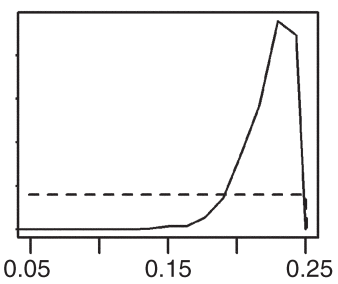

$\beta_{e}$

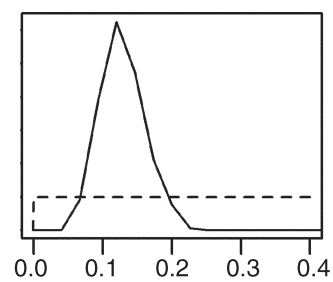

$\beta_{k 0}(\mathrm{~m} / \mathrm{d})$

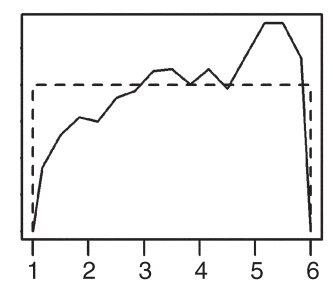

$r_{\mathrm{Qg}}$
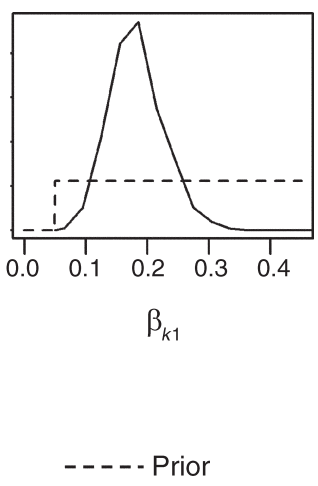

-Posterior

FIG. 4. Prior and posterior probability distributions for calibrated mechanistic model parameters (as described in Table 1). The $y$-axes represent relative probability, parameters are unitless unless indicated otherwise.

\section{RESULTS}

\section{Model calibration and validation results}

Seven mechanistic model parameters were estimated probabilistically through Bayesian inference. The likely range for each parameter is represented by its posterior distribution (Fig. 4). Three of these parameters, $v_{\mathrm{s}}, \omega$, and $B$, primarily control oxygen dynamics within the model. The best estimate (i.e., mean of the posterior distribution) for effective settling velocity, $v_{\mathrm{s}}$, is $0.19 \mathrm{~m} /$ d. This rate corresponds to $11-17 \mathrm{~m}$ of settling over 2-3 months, suggesting a substantial flux of organic material through the pycnocline, consistent with the hypothesis that spring nutrient loads affect midsummer hypoxia. As expected, this effective settling rate is less than fieldmeasured particle sinking rates (Dagg et al. 2007) because it also represents the biological processes related to converting inorganic nitrogen to phytoplankton and ultimately to detrital organic nitrogen. The best estimate for the oxygen-demand adjustment parameter, $\omega$, is 0.37 , suggesting that factors such as photosynthesis or off-shelf losses substantially reduce the effective oxygen demand of fluxed organic material. The best estimate for benthic oxygen demand, $B$, is $0.33 \mathrm{~g} \cdot \mathrm{m}^{-2} \cdot \mathrm{d}^{-1}$, shifted slightly higher than the prior distribution (mean of 0.28 $\mathrm{g} \cdot \mathrm{m}^{-2} \cdot \mathrm{d}^{-1}$ ) determined from the extensive field study by Lehrter et al. (2012). This is consistent with smaller field studies (Rowe 2001, McCarthy et al. 2013) that documented higher benthic oxygen demands than those documented by Lehrter et al. (2012).

The parameters $\beta_{\mathrm{e}}$ and $r_{\mathrm{Qg}}$ are related primarily to model hydrodynamics. The best estimate for the flow partitioning parameter, $\beta_{\mathrm{e}}$, is 0.22 , such that transport ranges from $94 \%$ eastward to $94 \%$ westward under mean east-west winds ranging from 2 to $-2 \mathrm{~m} / \mathrm{s}$, respectively. (Note that $\beta_{\mathrm{e}}$ was constrained by prior information to a maximum of 0.25 , because higher values would unrealistically result in flow partitions greater than $100 \%$.) The best estimate for the ratio of Gulf dilution flow to mean Mississippi River flow, $r_{\mathrm{Qg}}$, is 3.8 , but the posterior distribution is very similar to the prior distribution (in terms of both mean and variance), suggesting this parameter could not be well resolved within the model. While $r_{\mathrm{Qg}}$ could be set to a fixed value without significantly affecting model performance, allowing the parameter to vary acknowledges a source of mechanistic uncertainty.

The reaeration parameters, $\beta_{k 0}$ and $\beta_{k 1}$, are used to determine the reaeration rate, $k_{\mathrm{a}}$. Under conditions of no wind (or infinite freshwater flow), $k_{\mathrm{a}}$ is equal to $\beta_{k 0}$. As freshwater flows decrease and wind stresses increase, $k_{\mathrm{a}}$ increases as a function of $\beta_{k 1}$ (Eq. 6). Based on the calibrated model, reaeration rates (by cruise) range from 0.16 to 0.53 and 0.14 to $0.37 \mathrm{~m} / \mathrm{d}$ for the west and east shelf sections, respectively. Overall, mean reaeration rates for the west and east shelf sections are 0.23 and $0.17 \mathrm{~m} / \mathrm{d}$, respectively, and their distributions are highly right-skewed. The highest reaeration rates are for 1988, due to the combined effects of low freshwater flows (drought year for the Mississippi River basin) and high winds (tropical storm Beryl). The mean rates from this study are somewhat higher than the $0.1 \mathrm{~m} / \mathrm{d}$ mean July reaeration rate from a modeling study by Justic et al. (1996) for a location near the center of the east shelf, where stratification would be expected to be particularly severe.

The statistical modeling framework allows for examination of correlation (i.e., dependence) among model parameters, where high correlations suggest parameters that cannot be well identified independently of each other (Omlin and Reichert 1999). The largest correlation 
is between $\omega$ and $\beta_{k 0}\left(r^{2}=0.65\right)$. This correlation is expected because these parameters have similar but opposite effects on DO levels. Other parameter pairings with notable correlations $\left(r^{2}>0.5\right)$ are $v_{\mathrm{s}}$ and $r_{\mathrm{Qg}}, B$ and $\beta_{k 0}$, and $B$ and $\beta_{k 1}$. Correlation among parameters could be avoided by setting some parameters to fixed values, but by allowing these correlations, uncertainty about the relative importance of mechanistic drivers is represented within the model.

Overall, the (full) model explains $75 \%$ and $76 \%$ of the variability in BWDO concentration on the west and east shelf sections, respectively. The model's residual standard deviations, $\sigma_{\operatorname{mech}(j)}$, were determined through Bayesian inference to be 0.35 and $0.31 \mathrm{mg} / \mathrm{L}$ for the west and east shelf sections, respectively. The robustness of the model was tested using leave-one-out and threefold cross-validation (CV) exercises (Chatfield 2006). For the leave-one-out CV, the mean BWDO for each cruise was predicted after removing that cruise from the calibration data set and recalibrating the model to the remaining data. Compared to full-model performance, the leave-one-out $\mathrm{CV}$ performance is a better measure of how well the model will perform when predicting future (out-of-sample) conditions. For this test, the model explains $72 \%$ of the variability in BWDO on each of the two shelf sections (Fig. 5), such that performance is only modestly diminished relative to the full model, suggesting the model is robust. In the threefold CV, three nine-year periods (1985-1993, 1994-2002, and 2003-2011) were, in turn, removed from the calibration data set and then predicted after the model was recalibrated to the remaining observations. Compared to the leave-one-out $\mathrm{CV}$, this exercise considers how robust the model is to potential longterm system variability. Here, the model explains $70 \%$ and $67 \%$ of the variability on the west and east shelf sections, respectively, again indicating only a modest reduction in model performance. Some reduction in performance is expected in this case, given that the calibration data set has been reduced to only 18 years for the threefold test, and these results generally confirm that the model is robust (i.e., not over-parameterized).

The 27-year mean vertical carbon fluxes determined by the model are 0.14 and $0.27 \mathrm{~g} \mathrm{C} \cdot \mathrm{m}^{-2} \cdot \mathrm{d}^{-1}$ for the west and east shelf sections, respectively. The modeled east shelf carbon flux conforms well with prior information for east shelf carbon flux, $\mathrm{N}(0.29,0.05) \mathrm{g} \mathrm{C} \cdot \mathrm{m}^{-2} \cdot \mathrm{d}^{-1}$. The carbon flux on the west shelf is expected to be lower, as it is further removed from the river outfalls, on average. Modeled carbon fluxes can also be compared to measured water-column respiration rates. An extensive study by Murrell et al. (2013) reports lower-layer watercolumn respiration rates averaging $0.22 \mathrm{~g} \mathrm{O} \cdot \mathrm{m}^{-3} \cdot \mathrm{d}^{-1}$ over the entire shelf. Assuming a $10-\mathrm{m}$ thick lower layer and an $R_{\mathrm{O}: \mathrm{C}}$ of $3.5 \mathrm{~g} \mathrm{O} / \mathrm{g} \mathrm{C}$, this is equivalent to an areal rate of $0.63 \mathrm{~g} \mathrm{C} \cdot \mathrm{m}^{-2} \cdot \mathrm{d}^{-1}$, considerably higher than the modeled carbon flux rates. This may be due to lowerlayer photosynthesis, resulting in higher measured rates

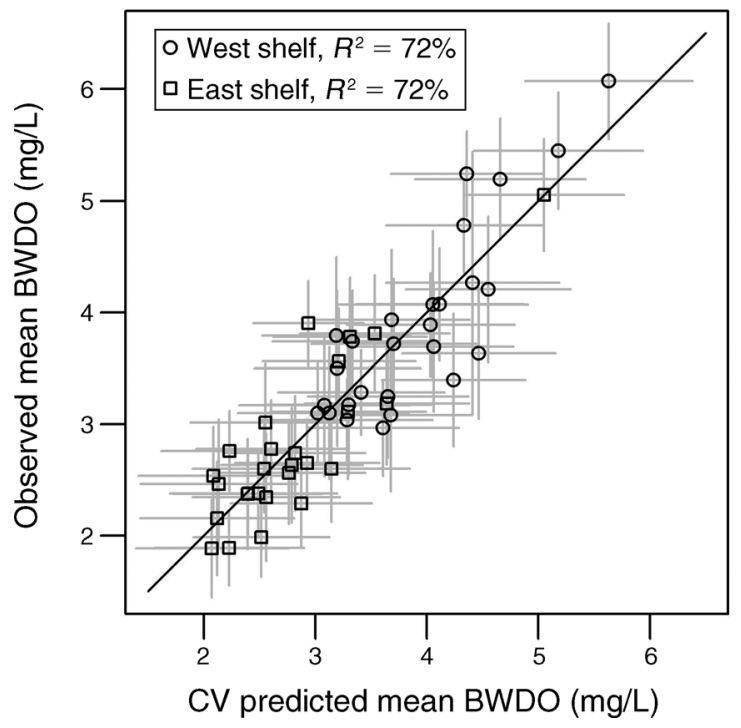

FIG. 5. Observed (geostatistical) mean BWDO vs. leaveone-out cross-validation $(\mathrm{CV})$ model predictions for the west and east shelf sections, with $95 \%$ prediction intervals.

of both oxygen production and respiration in the subpycnocline (but no net increase in oxygen demand). Also, respiration rates and the relative contributions of surface and benthic respiration have varied substantially across different Gulf field studies, possibly due to differences in experimental design (McCarthy et al. 2013).

\section{Comparison to linear regression modeling}

Linear regression (LR) is a modeling approach that has been used in several previous Gulf hypoxia studies (Greene et al. 2009, Forrest et al. 2011, Turner et al. 2012). These previous modeling studies are not directly comparable to this study, as they focus on somewhat different hypoxia metrics. However, the effectiveness of LR and parsimonious mechanistic modeling for predicting mean BWDO on the east and west shelf sections can be compared here. To enable this comparison, LR models were developed for the east and west shelf sections using the candidate predictor variables from this study (i.e., flow, load, concentration, wind velocity, and wind stress). To help avoid over-parameterization, only variables selected from the Akaike information criterion (AIC) and Bayesian information criterion (BIC) are used, where BIC results in more parsimonious models than does AIC (Faraway 2005). Models are compared in terms of percentage of variance explained $\left(R^{2}\right)$, based on both full-model and leave-one-out $\mathrm{CV}$ predictions.

For the variables considered in this study, the parsimonious mechanistic model outperforms the LR models, especially in CV mode (Table 2). There are two primary reasons why this is likely to be the case. First, plots of observed vs. predicted values for the LRs (not shown) demonstrate a nonlinear pattern in residuals, 
TABLE 2. Variance explained $\left(R^{2}\right)$ by mechanistic and linear regression (LR) models, based on full-model and leave-one-out cross-validation (CV) predictions.

\begin{tabular}{lrr}
\hline \hline \multicolumn{1}{c}{ Model } & $\begin{array}{c}R^{2} \\
(\%)\end{array}$ & $\begin{array}{c}\mathrm{CV} R^{2} \\
(\%)\end{array}$ \\
\hline West shelf results & & \\
Mechanistic model (all variables) & 75 & 72 \\
West shelf LR with AIC variables: $L_{\mathrm{rN}}($ Miss $), W_{\mathrm{e}}$ (spring), $W_{\mathrm{e}}$ (summer), $\tau($ east) & 66 & 31 \\
West shelf LR with BIC variables: $L_{\mathrm{rN}}$ (Miss), $W_{\mathrm{e}}$ (spring), $W_{\mathrm{e}}$ (summer) & 62 & 43 \\
East shelf results & & \\
Mechanistic model (all variables) & 76 & 72 \\
East shelf LR with AIC variables: $L_{\mathrm{rN}}$ (Miss), $W_{\mathrm{e}}$ (summer), $\tau$ (west), $\tau($ east) & 72 & 51 \\
East shelf LR with BIC variables: $L_{\mathrm{rN}}\left(\right.$ Miss), $W_{\mathrm{e}}$ (summer), $\tau$ (east) & 69 & 54 \\
\hline
\end{tabular}

Notes: AIC refers to Aikake information criterion, BIC to Bayesian information criterion. $L_{\mathrm{rN}}$ is the river load of nitrogen, $W_{\mathrm{e}}$ the mean east-west wind velocity, and Miss the Mississippi River.

indicating the system is not well represented by linear combinations of the available predictor variables. The mechanistic model performs better in this respect (Fig. 5), likely because its nonlinear relationships better approximate the true functioning of the system. Second, the CV performance of the LRs tends to decrease when more predictor variables are included within the model (i.e., BIC results are better than AIC), suggesting overparameterization issues. The mechanistic model includes more predictor variables than the LR models, but the impact of these variables is regulated by the prior information and biophysical structure of the model. Furthermore, in the mechanistic model, the differential response in BWDO for the two shelf sections is determined based on biophysical properties (e.g., the relative position and areal extent of each shelf section), such that the model can be calibrated to both shelf sections (44 geostatistical observations) without relying on shelf-specific calibration parameters. Because the LR models do not benefit from these mechanistic relationships, it is generally necessary to fit separate regressions to the different shelf sections, such that each LR is based on only 27 observations. This smaller sample size makes the LR model parameterizations more sensitive (less robust) to exclusion of individual cruises, which is reflected in the $\mathrm{CV}$ results.

\section{$B W D O$ sensitivity to stratification and nutrient loading}

The model includes spring inputs related to seasonal nutrient loading and summer inputs related to stratification. Understanding the relative roles of these two inputs in determining hypoxic severity is an important scientific and management question (Justic et al. 2007). By holding one of these input sets constant (at 27-year mean values), while allowing the other to vary, it is possible to examine the relative roles of these two drivers of hypoxia. As shown in Fig. 6, both drivers substantially impact the year-to-year variability in mean BWDO. An influence metric for quantifying the impact is determined by calculating the standard deviation of the 27 predicted BWDO values, under the different model input conditions. The influence metrics for nutrient inputs (based on spring loads, spring flows, and spring winds) and stratification inputs (based on summer flows and summer winds/wind stresses) are 0.24 and $0.53 \mathrm{mg} / \mathrm{L}$ for the west shelf, respectively; and 0.33 and $0.46 \mathrm{mg} / \mathrm{L}$ for the east shelf, respectively. These results suggest a somewhat larger role for stratification in explaining year-to-year variability in BWDO. However, when the uncertainty (and correlation) in the mechanistic model parameters is accounted for, the differences between the nutrient and stratification influence metrics are only significant for the west shelf (i.e., there is a $13 \%$ probability that the role of nutrients exceeds that of stratification on the east shelf). The west

- Using all drivers

$\times$ Using spring drivers only (nutrient effect)

+ Using summer drivers only (stratification effect)

- Using no drivers (all factors held at mean values)
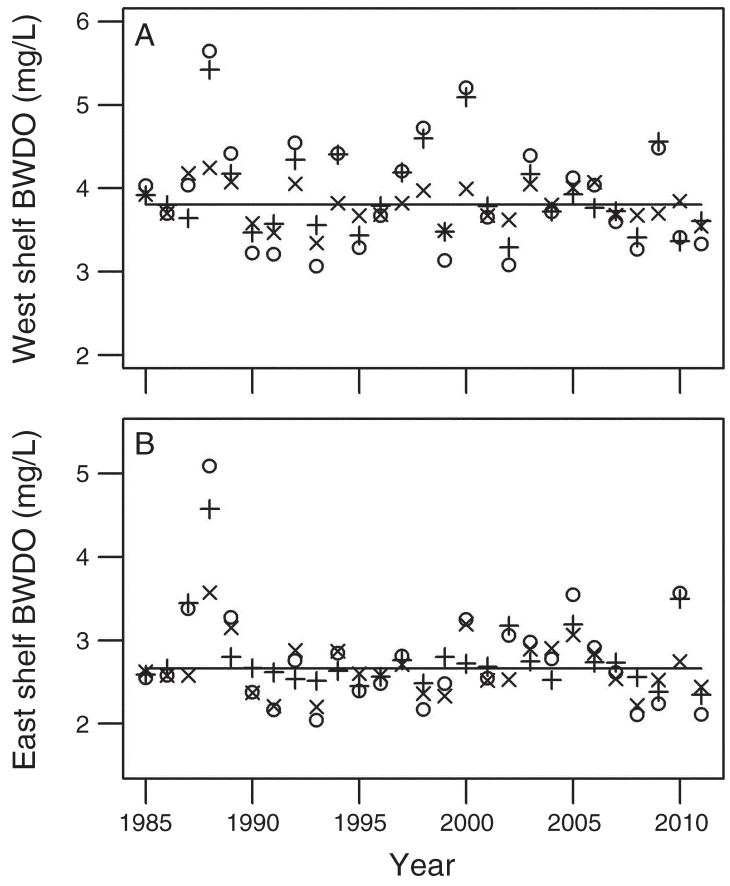

FIG. 6. Model-predicted mean BWDO for the (A) west and (B) east shelf sections based on different mechanistic drivers (holding other factors at 27-year mean values). 
shelf appears heavily influenced by weather conditions resulting in minimal stratification (i.e., high model reaeration) in 1988 due to drought and wind stress, and in 1998, 2000, and 2009, due to unusually strong westerly winds.

It should be emphasized that the nutrient effects presented in this analysis (i.e., Fig. 6) are related only to how spring nutrient loads regulate the year-to-year variability in BWDO for the 27-year study period, not how nutrient loads may further regulate hypoxia under potential long-term nutrient loading reduction (or intensification) scenarios. In particular, long-term changes in nutrient loading would be expected to affect benthic oxygen demand, and thus produce larger impacts on BWDO. An analysis of how changing benthic oxygen demands could affect BWDO is included in Results: Hypoxic area prediction and nutrient reduction scenarios.

\section{Temporal trends in hypoxia}

Previous empirical and simple mechanistic modeling studies (Turner et al. 2008, Greene et al. 2009, Liu et al. 2010) have suggested that Gulf hypoxia has become more severe over time, independent of spring nutrient loads. In this study, model residuals were analyzed for signs of change in the system's susceptibility to hypoxia over the 27-year study period, where a negative temporal trend or shift in residuals would indicate increasing susceptibility. Temporal trends in residuals were found to be statistically insignificant on both shelf sections, and a visual examination of residuals did not indicate any abrupt temporal transitions. Model residuals can also be compared with nutrient loads from the preceding year (July-June loads), as shown in Fig. 7. Here, the residuals are area-weighted averages of the two shelf sections (west shelf receives more weight). However, no pattern between residuals and loads (or multiyear averages of these loads) was identified. Thus, the model does not indicate any long-term change in the system's susceptibility to hypoxia over the 27 -year study period.

\section{Hypoxic area prediction and nutrient reduction scenarios}

Predicted BWDO concentrations can be converted to predicted hypoxic areas using Eqs. 8 and 9. Based on these relationships, the model explains $68 \%$ and $73 \%$ of year-to-year variability in hypoxic area on the west and east shelf sections, respectively. Aggregating the results, the model explains $70 \%$ of the variability in total hypoxic area. Model performance is greater for BWDO than hypoxic area because of the nonlinear relationship between these variables, such that model errors for years of relatively low BWDO are amplified when converted to hypoxic area.

Using the model and the relationship between BWDO and hypoxic area, it is possible to examine how nutrient load reductions would affect the average areal extent of hypoxia (for the 27-year study period). The reductions are relative to the historical bioavailable spring nitrogen

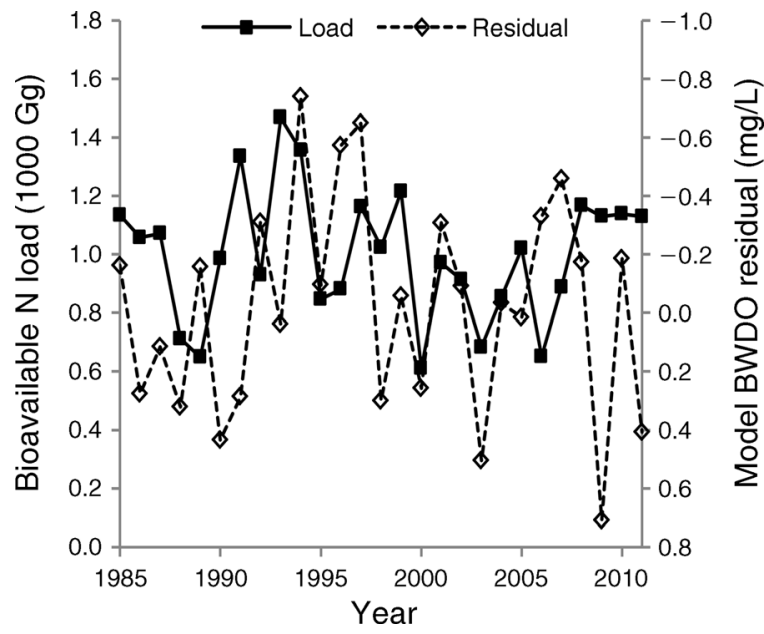

FIG. 7. Area-weighted mechanistic model residuals (observed - predicted) compared with Mississippi River bioavailable nitrogen load from preceding year (July-June), over time.

load, averaging $133 \mathrm{Gg} /$ month for the study period. An important consideration in this analysis is whether the nutrient loading reductions will also result in reductions in benthic oxygen demand. If benthic oxygen demand remains constant, then even an $80 \%$ reduction in nutrient loading (Fig. 8A) will still result in a mean total hypoxic area greater than $5000 \mathrm{~km}^{2}$. However, if nutrient loading reductions are accompanied by proportional reductions in benthic oxygen demand (Fig. $8 \mathrm{~B})$, then a $45 \% \pm 5 \%$ (mean $\pm \mathrm{CI}$ ) reduction in nutrient loading would achieve a mean hypoxic area of $5000 \mathrm{~km}^{2}$. While one would expect benthic oxygen demand to decline as nutrient loading to the system is diminished, the degree of this decline and the time scale over which it would occur are not clear.

\section{Discussion}

Methodologically, this study demonstrates the benefits of using Bayesian inference for calibrating mechanistic environmental models. First, the Bayesian approach readily allowed for probabilistically estimating the parameters of a nonlinear model, such as was developed here. Second, the approach provided a systematic means of incorporating prior information about biophysical rates (with associated uncertainties), as determined from previous studies. Third, compared to more traditional approaches, model uncertainties were not constrained to follow normal (Gaussian) distributions, allowing more flexibility in how parameters were represented (Fig. 4). The benefits of the Bayesian modeling framework have been demonstrated in previous hypoxia modeling studies by Liu et al. (2010) and Stow et al. (2005), and this study builds on that work by applying the Bayesian framework to a richer mechanistic model, capable of integrating a larger suite of environmental inputs. 


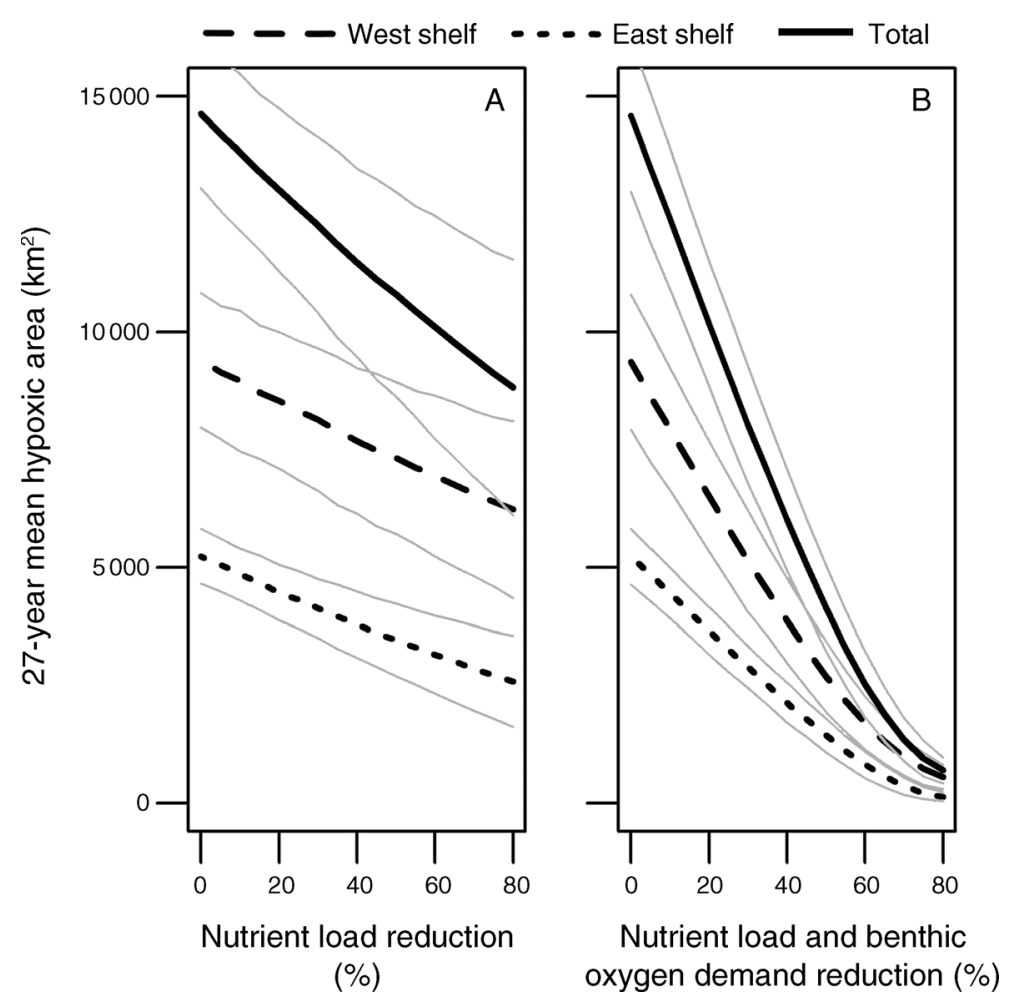

FIG. 8. Mean (over 27 years) hypoxic areas (with 95\% credible intervals shown in gray) for west shelf, east shelf, and total shelf under (A) spring nutrient load reductions alone and (B) nutrient load reductions with proportional benthic oxygen demand reductions.

In addition, this is the first Gulf hypoxia modeling study to systematically test the model's predictive performance for observations not included within the calibration data set (using CV). While the mechanistic model developed here performed well in $\mathrm{CV}$, linear regression models developed from the same input variables performed substantially less well (Table 2). This is noteworthy, given that none of the previous Gulf hypoxia regression models have been formally validated. However, models used to make annual hypoxia forecasts (Liu et al. 2010, Turner et al. 2012) have received some degree of validation by comparing these blind annual forecasts to observed values (Evans and Scavia 2011). In the future, systematic validation exercises could potentially be used to test and lend additional credibility to such models.

This work provides new insights into the relative roles of benthic and water-column oxygen demands. In the model, benthic oxygen demand is represented by a constant value, such that it is not related to seasonal nutrient loading, whereas water-column oxygen demand is directly related to the spring nitrogen load. The calibrated model suggests benthic oxygen demand is approximately $0.33 \mathrm{~g} \cdot \mathrm{m}^{-2} \cdot \mathrm{d}^{-1}$. In comparison, net water-column oxygen demands are estimated to be $0.18 \mathrm{~g} \cdot \mathrm{m}^{-2} \cdot \mathrm{d}^{-1}$ and $0.34 \mathrm{~g} \cdot \mathrm{m}^{-2} \cdot \mathrm{d}^{-1}$ on average, for the west and east shelf sections, respectively. The relatively low water-column oxygen demand on the west shelf section suggests the west shelf is less responsive to the year-to-year variability in spring nitrogen load, as also suggested by Hetland and DiMarco (2008). For example, the model indicates a $50 \%$ reduction in spring nitrogen produces approximately $22 \%$ and $34 \%$ reductions in west and east shelf hypoxic area, respectively (Fig. 8A). If benthic oxygen demand is also reduced, then much larger reductions in hypoxic area can be expected for both shelf sections (Fig. 8B). While benthic oxygen demand would be expected to decrease under sustained nutrient loading reductions, this cannot be easily verified because nutrient loads have remained near historically high levels throughout the study period (Goolsby and Battaglin 2001).

One way to infer how benthic oxygen demand has changed over time is to consider paleoindicators of hypoxic severity, which are determined from shelf sediment cores (Rabalais et al. 2007b). The bacterial pigment concentrations and foraminiferal community metrics measured in these cores provide clues as to how the severity of hypoxia has changed over the last century. Several core studies indicate that paleoindicators of hypoxia have increased greatly (approximately two-threefold) since the mid-1900s (Nelsen et al. 1994, Chen et al. 2001, Osterman et al. 2005, Platon et al. 2005). Meanwhile, in the mid-1900s, bioavailable nitrogen loading was approximately $50 \%$ less than at the time of this modeling study (Goolsby and Battaglin 
2001). If benthic oxygen demand was the same in the mid-1900s as today, then the model-predicted mid-1900s hypoxic area for the east shelf section (where most cores are taken) would be only $34 \%$ smaller than today (Fig. $8 \mathrm{~A})$, inconsistent with the large change in paleoindicators of hypoxia. However, if benthic oxygen demand was lower in the mid-1900s, then the model-predicted mid-1900s hypoxic area would be much smaller (similar to Fig. 8B), more consistent with the paleoindicator data. These results suggest that benthic oxygen demand has changed prior to the period of this study, and the direction of this change is consistent with the hypothesis that this demand is (at least partially) linked to longterm nutrient loading.

Contrary to previous long-term modeling studies (Turner et al. 2008, Greene et al. 2009, Liu et al. 2010), this study does not indicate any significant temporal trend or shift in the system's propensity for hypoxia formation over the study period. This is likely due, in part, to the use of revised hypoxia metrics that show less increase in hypoxic spatial extent over the 27year study period (Obenour et al. 2013, Scavia et al. 2013). However, we note that model residuals were largely negative (i.e., BWDO was over-predicted) from 1994 to 1997 on both shelf sections (Fig. 7), perhaps because the large loads of 1993 and 1994 resulted in an accumulation of organic matter that persisted in following years as additional benthic oxygen demand. While this hypothesis cannot be verified by this study alone, the unusually severe impact of the 1993 flood on Gulf water quality has been noted previously (Rabalais et al. 2007a). It is also noted that new estimates of hypoxic volume (Obenour et al. 2013) suggest a somewhat larger increase (relative to hypoxic area and mean BWDO) over the study period, and extending this model to predict hypoxic volume may be beneficial to future research.

The model results support the paradigm that both seasonal nutrient loading and stratification contribute substantially to the year-to-year variability in hypoxia. Stratification is represented by the reaeration sub-model (Eq. 6), which is a function of summer river discharge, summer east-west wind velocity, and wind stress. The role of stratification is found to be larger on the west shelf than on the east shelf (Fig. 6), consistent with the finding that seasonal nutrient loading contributes less to the total west shelf oxygen demand. A previous empirical modeling study by Obenour et al. (2012), based on site-specific observations of BWDO, indicated that stratification and seasonal nutrient loading have approximately equal influence on the year-to-year variability in hypoxia. The larger role of stratification in this study is likely due, in part, to the shelf division, because summer east-west wind velocities impact stratification oppositely on the west and east shelf sections, such that these impacts partially compensate for each other when studying the shelf as a whole. Nutrient loading can also be distributed to the east or west, based on spring wind velocity, but spring winds are more consistently easterly. Nonetheless, by explicitly accounting for stratification and benthic oxygen demand, our model suggests that hypoxic area is less responsive to seasonal nutrient loading (Fig. 8A) than previously thought (Greene et al. 2009, Turner et al. 2012, Scavia et al. 2013).

The parsimonious modeling approach used in this study is not without limitations. The use of a steadystate model solution, and the associated assumption that spring loading determines midsummer water-column oxygen demands, is sensible because of the time lag between nutrient input and organic matter decay. However, summer conditions may nevertheless influence the intensity and spatial distribution of oxygen demands on the shelf (Feng et al. 2013). If summer conditions consistently modify oxygen demands in a particular direction (positively or negatively), then some of the parameter estimates obtained in the model may be biased. In addition, this study assumes that benthic oxygen demand increases linearly with water-column DO. While this may be approximately correct (Rowe 2001, Lehrter et al. 2012), it is possible that benthic oxygen demand saturates at water-column DO levels above $4 \mathrm{mg} / \mathrm{L}$ (Hetland and DiMarco 2008), such that modeled benthic oxygen demand may be overrepresented in years of high water-column DO. As with virtually all models, the model developed here is a simplification of reality, such that it is subject to future refinements, especially as more data and information about biophysical rates become available. Despite such uncertainties, we believe this model captures the primary mechanistic processes leading to hypoxia formation; and it has a demonstrated capacity for skillfully predicting BWDO based on carbon fluxes, oxygen demands, and reaeration rates that compare well with previous monitoring and biogeochemical process studies.

Multiple previous Gulf modeling studies (Greene et al. 2009, Turner et al. 2012, Scavia et al. 2013) have suggested that nutrient loading reductions ranging from $\sim 45 \%$ to $65 \%$ will be sufficient for achieving the Mississippi River/Gulf of Mexico Task Force goal of reducing mean hypoxic area to $5000 \mathrm{~km}^{2}$ or less (EPA 2008). However, our modeling results indicate that such reductions will be insufficient, at least in the short term (Fig. 8A). Unlike the previous studies, our study explicitly accounts for long-term benthic oxygen demands, which are found to be comparable in magnitude to the oxygen demands generated from seasonal nutrient loading. Thus, benthic oxygen demands must also be reduced in order to achieve the Task Force goal (Fig. 8B). While a comparison of our modeling results with paleoindicators of hypoxia suggests a linkage between long-term nutrient loading and benthic oxygen demand, the magnitude and temporal lag of this linkage remain highly uncertain. As such, this study indicates the need for further research into factors that control the intensity of benthic oxygen demand on the Gulf shelf. 
More detailed biogeochemical modeling studies, supported by appropriate monitoring data, could potentially be developed to explore how benthic oxygen demands will respond to changes in nutrient loading over decadal time scales. The relevant mechanistic relationships from such studies could then be distilled into the probabilistic modeling framework presented here, allowing for more informative long-term scenario forecasts.

\section{ACKNOWLEDGMENTS}

The work was supported by the United States Environmental Protection Agency (U.S. EPA) STAR Fellowship program, the National Oceanic and Atmospheric Administration (NOAA) Center for Sponsored Coastal Ocean Research grant NA09NOS4780204, and the Graham Sustainability Institute. This is NGOMEX Contribution 184. The manuscript benefited from reviews by Valeriy Ivanov and R. Eugene Turner.

\section{Literature Cited}

Beck, M. B. 1987. Water-quality modeling: a review of the analysis of uncertainty. Water Resources Research 23:13931442.

Bierman, V. J., S. C. Hinz, D. W. Zhu, W. J. Wiseman, N. N. Rabalais, and R. E. Turner. 1994. A preliminary mass balance model of primary productivity and dissolved oxygen in the Mississippi River Plume/Inner Gulf Shelf region. Estuaries 17:886-899.

Bushaw, K. L., R. G. Zepp, M. A. Tarr, D. Schulz-Jander, R. A. Bourbonniere, R. E. Hodson, W. L. Miller, D. A. Bronk, and M. A. Moran. 1996. Photochemical release of biologically available nitrogen from aquatic dissolved organic matter. Nature 381:404-407.

Chapra, S. C. 1997. Surface water-quality modeling. McGrawHill, New York, New York, USA.

Chatfield, C. 2006. Model uncertainty. Encyclopedia of Environmetrics. 4. John Wiley and Sons, Hoboken, New Jersey, USA.

Chen, N. H., T. S. Bianchi, B. A. McKee, and J. M. Bland. 2001. Historical trends of hypoxia on the Louisiana shelf: application of pigments as biomarkers. Organic Geochemistry $32: 543-561$.

Cho, K. W., R. O. Reid, and W. D. Nowlin. 1998. Objectively mapped stream function fields on the Texas-Louisiana shelf based on 32 months of moored current meter data. Journal of Geophysical Research-Oceans 103:10377-10390.

Clark, J. S., et al. 2001. Ecological forecasts: an emerging imperative. Science 293:657-660.

Dagg, M. J., J. W. Ammerman, R. M. W. Amon, W. S. Gardner, R. E. Green, and S. E. Lohrenz. 2007. A review of water column processes influencing hypoxia in the northern Gulf of Mexico. Estuaries and Coasts 30:735-752.

Diaz, R. J., and R. Rosenberg. 2008. Spreading dead zones and consequences for marine ecosystems. Science 321:926-929.

EPA. 2008. Mississippi River/Gulf of Mexico watershed nutrient task force Gulf hypoxia action plan 2008 for reducing mitigating, and controlling hypoxia in the northern Gulf of Mexico and improving water quality in the Mississippi River Basin. U.S. Environmental Protection Agency, Office of Wetlands, Oceans, and Watersheds, Washington, D.C., USA.

Evans, M. A., and D. Scavia. 2011. Forecasting hypoxia in the Chesapeake Bay and Gulf of Mexico: model accuracy, precision, and sensitivity to ecosystem change. Environmental Research Letters 6:015001.

Faraway, J. J. 2005. Linear models with R. Chapman and Hall/ CRC, London, UK.
Feng, Y., S. F. DiMarco, and G. A. Jackson. 2012. Relative role of wind forcing and riverine nutrient input on the extent of hypoxia in the northern Gulf of Mexico. Geophysical Research Letters 39:L09601.

Feng, Y., K. Fennel, G. A. Jackson, S. F. DiMarco, and R. D. Hetland. 2013. A model study of the response of hypoxia to upwelling-favorable wind on the northern Gulf of Mexico shelf. Journal of Marine Systems 131:63-73.

Fennel, K., J. Hu, A. Laurent, M. Marta-Almeida, and R. Hetland. 2013. Sensitivity of hypoxia predictions for the northern Gulf of Mexico to sediment oxygen consumption and model nesting. Journal of Geophysical ResearchOceans 118(2):990-1002.

Forrest, D. R., R. D. Hetland, and S. F. DiMarco. 2011. Multivariable statistical regression models of the areal extent of hypoxia over the Texas-Louisiana continental shelf. Environmental Research Letters 6:045002.

Gelman, A., and J. Hill. 2007. Data analysis using regression and multilevel/hierarchical models. Cambridge University Press, Cambridge, UK.

Goolsby, D. A., and W. A. Battaglin. 2001. Long-term changes in concentrations and flux of nitrogen in the Mississippi River Basin, USA. Hydrological Processes 15:1209-1226.

Greene, R. M., J. C. Lehrter, and J. D. Hagy. 2009. Multiple regression models for hindcasting and forecasting midsummer hypoxia in the Gulf of Mexico. Ecological Applications 19:1161-1175.

Hernes, P. J., and R. Benner. 2003. Photochemical and microbial degradation of dissolved lignin phenols: implications for the fate of terrigenous dissolved organic matter in marine environments. Journal of Geophysical ResearchOceans 108.

Hetland, R. D., and S. F. DiMarco. 2008. How does the character of oxygen demand control the structure of hypoxia on the Texas-Louisiana continental shelf? Journal of Marine Systems 70:49-62.

Justic, D., V. J. Bierman, D. Scavia, and R. D. Hetland. 2007. Forecasting Gulf's hypoxia: the next 50 years? Estuaries and Coasts 30:791-801.

Justic, D., N. N. Rabalais, and R. E. Turner. 1996. Effects of climate change on hypoxia in coastal waters: a doubled $\mathrm{CO}_{2}$ scenario for the northern Gulf of Mexico. Limnology and Oceanography 41:992-1003.

Justic, D., N. N. Rabalais, and R. E. Turner. 2002. Modeling the impacts of decadal changes in riverine nutrient fluxes on coastal eutrophication near the Mississippi River Delta. Ecological Modelling 152:33-46.

Justic, D., and L. Wang. 2013. Assessing temporal and spatial variability of hypoxia over the inner Louisiana-upper Texas shelf: application of an unstructured-grid three-dimensional coupled hydrodynamic-water quality model. Continental Shelf Research 72:163-179.

Lehrter, J. C., D. L. Beddick, R. Devereux, D. F. Yates, and M. C. Murrell. 2012. Sediment-water fluxes of dissolved inorganic carbon, $\mathrm{O}_{2}$, nutrients, and $\mathrm{N}_{2}$ from the hypoxic region of the Louisiana continental shelf. Biogeochemistry 109:233-252.

Lehrter, J. C., M. C. Murrell, and J. C. Kurtz. 2009. Interactions between freshwater input, light, and phytoplankton dynamics on the Louisiana continental shelf. Continental Shelf Research 29:1861-1872.

Liu, Y., M. A. Evans, and D. Scavia. 2010. Gulf of Mexico hypoxia: exploring increasing sensitivity to nitrogen loads. Environmental Science and Technology 44:5836-5841.

Lunn, D. J., A. Thomas, N. Best, and D. Spiegelhalter. 2000. WinBUGS - a Bayesian modelling framework: concepts, structure, and extensibility. Statistics and Computing 10:325-337.

McCarthy, M. J., S. A. Carini, Z. F. Liu, N. E. Ostrom, and W. S. Gardner. 2013. Oxygen consumption in the water column and sediments of the northern Gulf of Mexico 
hypoxic zone. Estuarine Coastal and Shelf Science 123:4653.

Murrell, M. C., R. S. Stanley, J. C. Lehrter, and J. D. Hagy. 2013. Plankton community respiration, net ecosystem metabolism, and oxygen dynamics on the Louisiana continental shelf: implications for hypoxia. Continental Shelf Research 52:27-38.

Nelsen, T. A., P. Blackwelder, T. Hood, B. McKee, N. Romer, C. Alvarezzarikian, and S. Metz. 1994. Time-based correlation of biogenic, lithogenic and authigenic sediment components with anthropogenic inputs in the Gulf of Mexico NECOP study area. Estuaries 17:873-885.

Obenour, D. R., A. M. Michalak, Y. Zhou, and D. Scavia. 2012. Quantifying the impacts of stratification and nutrient loading on hypoxia in the northern Gulf of Mexico. Environmental Science and Technology 46:5489-5496.

Obenour, D. R., D. Scavia, N. N. Rabalais, R. E. Turner, and A. M. Michalak. 2013. Retrospective analysis of midsummer hypoxic area and volume in the northern gulf of Mexico, 1985-2011. Environmental Science and Technology 47:98089815.

Omlin, M., and P. Reichert. 1999. A comparison of techniques for the estimation of model prediction uncertainty. Ecological Modelling 115:45-59.

Osterman, L. E., R. Z. Poore, P. W. Swarzenski, and R. E. Turner. 2005. Reconstructing a $180 \mathrm{yr}$ record of natural and anthropogenic induced low-oxygen conditions from Louisiana continental shelf sediments. Geology 33:329-332.

Platon, E., B. K. Sen Gupta, N. N. Rabalais, and R. E. Turner. 2005. Effect of seasonal hypoxia on the benthic foraminiferal community of the Louisiana inner continental shelf. The 20th century record. Marine Micropaleontology 54:263-283.

R Development Core Team. 2008. R: A language and environment for statistical computing. R Foundation for Statistical Computing, Vienna, Austria. http://www. R-project.org

Rabalais, N. N., R. J. Diaz, L. A. Levin, R. E. Turner, D. Gilbert, and J. Zhang. 2010. Dynamics and distribution of natural and human-caused hypoxia. Biogeosciences 7:585619.

Rabalais, N. N., R. E. Turner, D. Justic, Q. Dortch, and W. J. Wiseman. 1999. Characterization of hypoxia. Coastal ocean program decision analysis series no. 15. National Oceanic and Atmospheric Administration (NOAA), Silver Spring, Maryland, USA.

Rabalais, N. N., R. E. Turner, B. K. Sen Gupta, D. F. Boesch, P. Chapman, and M. C. Murrell. 2007a. Hypoxia in the northern Gulf of Mexico: does the science support the plan to reduce, mitigate, and control hypoxia? Estuaries and Coasts 30:753-772.

Rabalais, N. N., R. E. Turner, B. K. Sen Gupta, E. Platon, and M. L. Parsons. 2007b. Sediments tell the history of eutrophication and hypoxia in the northern Gulf of Mexico. Ecological Applications 17(Supplement):S129-S143.

Reckhow, K. H. 2003. On the need for uncertainty assessment in TMDL modeling and implementation. Journal of Water Resources Planning and Management 129:245-246.

Redalje, D. G., S. E. Lohrenz, and G. L. Fahnenstiel. 1994. The relationship between primary production and the vertical export of particulate organic-matter in a river-impacted coastal ecosystem. Estuaries 17:829-838.

Redfield, A. C., B. H. Ketchum, and F. A. Richards. 1963. The influence of organisms on the composition of seawater. Pages 26-77 in M. N. Hill, editor. The sea. John Wiley, Hoboken, New Jersey, USA.

Rowe, G. T. 2001. Seasonal hypoxia in the bottom water off the Mississippi River delta. Journal of Environmental Quality 30:281-290.
Runkel, R. L., C. G. Crawford, and T. A. Cohn. 2004. Load estimator (LOADEST): a FORTRAN program for estimating constituent loads in streams and rivers. U.S. Department of the Interior, U.S. Geological Survey, Reston, Virginia, USA.

Scavia, D., and K. A. Donnelly. 2007. Reassessing hypoxia forecasts for the Gulf of Mexico. Environmental Science and Technology 41:8111-8117.

Scavia, D., M. A. Evans, and D. R. Obenour. 2013. A scenario and forecast model for Gulf of Mexico hypoxic area and volume. Environmental Science and Technology 47:1042310428.

Scavia, D., D. Justic, and V. J. Bierman. 2004. Reducing hypoxia in the Gulf of Mexico: advice from three models. Estuaries 27:419-425.

Scavia, D., N. N. Rabalais, R. E. Turner, D. Justic, and W. J. Wiseman. 2003. Predicting the response of Gulf of Mexico hypoxia to variations in Mississippi River nitrogen load. Limnology and Oceanography 48:951-956.

Stow, C. A., S. S. Qian, and J. K. Craig. 2005. Declining threshold for hypoxia in the Gulf of Mexico. Environmental Science and Technology 39:716-723.

Stow, C. A., K. H. Reckhow, S. S. Qian, E. C. Lamon, G. B. Arhonditsis, M. E. Borsuk, and D. Seo. 2007. Approaches to evaluate water quality model parameter uncertainty for adaptive tmdl implementation. Journal of the American Water Resources Association 43:1499-1507.

Strauss, J., E. L. Grossman, and S. F. DiMarco. 2012. Stable isotope characterization of hypoxia-susceptible waters on the Louisiana shelf: tracing freshwater discharge and benthic respiration. Continental Shelf Research 47:7-15.

Sturtz, S., U. Ligges, and A. E. Gelman. 2005. R2WinBUGS: a package for running WinBUGS from R. Journal of Statistical Software 12(3):1-16.

Turner, R. E., N. N. Rabalais, and D. Justic. 2006. Predicting summer hypoxia in the northern Gulf of Mexico: riverine N, $\mathrm{P}$, and Si loading. Marine Pollution Bulletin 52:139-148.

Turner, R. E., N. N. Rabalais, and D. Justic. 2008. Gulf of Mexico hypoxia: alternate states and a legacy. Environmental Science and Technology 42:2323-2327.

Turner, R. E., N. N. Rabalais, and D. Justic. 2012. Predicting summer hypoxia in the northern Gulf of Mexico: redux. Marine Pollution Bulletin 64:319-324.

Walker, N. D., and N. N. Rabalais. 2006. Relationships among satellite chlorophyll a, river inputs, and hypoxia on the Louisiana continental shelf, Gulf of Mexico. Estuaries and Coasts 29:1081-1093.

Walker, N. D., W. J. Wiseman, L. J. Rouse, and A. Babin. 2005. Effects of river discharge, wind stress, and slope eddies on circulation and the satellite-observed structure of the Mississippi River plume. Journal of Coastal Research 21:1228-1244.

Wang, L. X., and D. Justic. 2009. A modeling study of the physical processes affecting the development of seasonal hypoxia over the inner Louisiana-Texas shelf: circulation and stratification. Continental Shelf Research 29:1464-1476.

Wiseman, W. J., N. N. Rabalais, R. E. Turner, S. P. Dinnel, and A. MacNaughton. 1997. Seasonal and interannual variability within the Louisiana coastal current: stratification and hypoxia. Journal of Marine Systems 12:237-248.

Zavala-Hidalgo, J., S. L. Morey, and J. J. O'Brien. 2003. Seasonal circulation on the western shelf of the Gulf of Mexico using a high-resolution numerical model. Journal of Geophysical Research-Oceans 108:C123389.

Zhang, X. Q., R. D. Hetland, M. Marta-Almeida, and S. F. DiMarco. 2012. A numerical investigation of the Mississippi and Atchafalaya freshwater transport, filling and flushing times on the Texas-Louisiana Shelf. Journal of Geophysical Research-Oceans 117:C11009. 